\title{
The effect of learning some safety skills in water on the Mental health indicators for infants *Dr/ Mohamed A. Makled
} Abstract:

The study aimed to identify the effect of learning some safety skills in water on the mental health indicators for infants. The researcher used the experimental approach using two groups, one is experimental and consists of (12) infants and is subject to the educational program and the second is composed of (12) infants and the most important results are the acquisition of children Experimental group for safety skills in water and improving mental health of the experimental group compared to the control group

Key words (infant swim, water safety skills, mental health, infants

\section{Introduction}

Swimming is a favorite sport for all different races and ages because of its appearances of joy and activity, and is even considered at the forefront of motor skills in general and sports especially in the educational field that the child prefers to learn during the first stages of life (osama rateb, 1999,33)

Swimming is one of the fun and enjoyable recreational activities, as it adds to its practitioners a unique color of joy, activity and vitality, as it is practiced at different stages of life in addition to the many benefits, as swimming has multiple benefits that accrue to the practicing individual with

many benefits in multiple aspects, which are recreational, psychological and therapeutic as well Physical, cognitive and physiological

(Mohamed hesain, 2009,12)

Participation in formal swimming lessons can reduce the risk of drowning by $88 \%$ among children aged 6 months to 4 years, and consideration should be given to including swimming lessons as part of a full preventive program, as many studies have shown that following swimming lessons At this age, the risk of drowning decreases to $40 \%$ in open water bodies for children participating in swimming (Brenner \&Etal 2009, 203)

* Dp. theories and applications of aquatic sports department Faculty of Physical Education for men Banha University.

Assiut Journal For Sport Science Arts 
Swimming children may result in better developments in balance, movement and assimilation techniques than children without swimming. (sigmundsson. et-al, 2010,428)

Also, the infants in swimming achieved the best achievement in the movement required to rotate 180 degrees and reach the underwater wall for children between the ages of (6-20) months. They also pointed out that swimming buoyancy for infants promotes the motor development of the child. (Zalazo, P.R, Weiss, 2006,25)

Children aged 5 to 5 years who participate in swimming lessons are more advanced in their physical and cognitive development compared to the group of children who did not practice swimming, as other results have appeared in social and linguistic development. (Jorgensen, R. \&et-al, 2011,19)

And children who practice swimming feel a sense of belonging and self-esteem in addition to being part of the group that helps in social development for him. The child also faces a great deal of tactical stimulation by resisting water on the entire body during swimming, which encourages nervous growth, weight gain and mental development through stimulation to touch pathways Neurological skin and vestibular nerve cells (Rosengren, 2004,66)

Childhood mental health problems are major indicators of public health, being the most common causes of learning disabilities and social impairment, and have a high risk of persistence in adolescence and the age of adults as strong evidence indicates neural development diseases before the age of three, for example autism spectrum disorders ( ASD) and attention deficit hyperactivity disorders (ADHD), while severe emotional and behavioral disorders such as attachment disorders may have a start in the first year of life. (Costello EJ, Egger H, Angold, 2005,204)

Prevention of early mental illnesses that may appear in preschool children may significantly reduce the development of symptoms of academic and emotional weakness and avoid attention deficit strikes, behavioral and psychological problems, and 
other disorders ( Janni \& Etal, 2016,83)

\section{Research problem :}

Through the previous presentation of theoretical readings and reference studies, and through the work of the researcher in the field of swimming sport, it was found that there is a so-called infant swim or what is called teaching safety skills in water for infants from the age of 12 months to 24 months and the spread of many academies specializing in teaching infants during Recently, through the researcher's briefing and follow-up on these academies, he did not find an educational program to teach the basic skills of swimming and water safety in infants

In addition to the great importance of the preventive role that swimming plays to avoid psychological problems that may be touched on children in advanced years, it can be avoided or reduce its impact in the future through the practice of swimming for infants, which the researcher also called for the necessity of learning about the role of learning basic skills for safety in water For babies with mental health level for them.

Aim of the research: The research aims to identify the effect of learning safety skills in water on the mental health of infants

\section{Hypotheses:}

1- There are statistically significant differences at the level of significance. 05 between the two dimensional measurements of the experimental group and the control in mental health.

2- There are statistically significant differences at the level of significance .05 between the pre and post measurements of the experimental group in the level of skill performance

\section{Method}

Design: The researcher used the experimental method for its suitability to the nature of the research and to achieve its goals.

sample: (12) for the experimental group in Banha Sports Club, (12) for the control group, and (12) for the reconnaissance group from the (Baby swimming Egypt) academy in the fifth assembly They were all in the stage of Sunni from (12 - 24) months

\section{Table (1)}


Homogeneity of research sample in the growth variables (age height - weight)

\begin{tabular}{|c|c|c|c|c|c|}
\hline & Min. & Max. & mean & Std. & Skew. \\
\hline Age & Ir... & 24.00 & $11 . r$. & $\varepsilon . \varepsilon$. & $\cdot r \leqslant \varepsilon$ \\
\hline the weight & $1 \cdot \ldots$ & $1 \% . V \cdot$ & IY.rT & $1 . \mu \cdot$ & $\cdot r_{q} r_{-}$ \\
\hline$\overline{\text { Length }}$ & $7 . .$. & $\wedge \tau . .$. & $V V .71$ & $1.1 V_{-}$ & $1.1 V_{-}$ \\
\hline
\end{tabular}

It is clear from Table (1) the homogeneity of the that the values of the torsional members of the research coefficients were confined sample in these variables.

between $( \pm 3)$, which indicates

Table (2)

Homogeneity of the research sample in the skill variables

\begin{tabular}{|c|c|c|c|c|c|}
\hline & Min. & Max. & mean & Std. & Skew. \\
\hline Trust in water & $\cdot$ & $r$ & $\because V Y V$ & $1 . \cdots$ & $1 . r v$ \\
\hline Mute self $15 \mathrm{w}$ & $\cdot$ & $r$ & $.7 \pi 7$ & 1.4 & 1.01 \\
\hline Buoyancy of the abdomen & $\cdot$ & $\bar{Y}$ & $\cdot . r 4 \pi$ & $.7 V \varepsilon$ & 1.01 \\
\hline Floating on the back & $\cdot$ & $r$ & $\because V Y V$ & $\because \vee \wedge \mathrm{T}$ & $.0 \mathrm{VT}$ \\
\hline Water circulation & $\dot{+}$ & 1 & $\cdot Y V Y$ &.$\leqslant 7 V$ & 1.11 \\
\hline Hold the edge of the pool & $\cdot$ & 1 &. .111 & $\cdot \varepsilon \cdot \varepsilon$ & 1.94 \\
\hline $\begin{array}{l}\text { Switch from floating on the back to } \\
\text { the abdomen }\end{array}$ & $\cdot$ & $T$ & $\cdot Y V T$ &.$\leq 7 V$ & 1.11 \\
\hline Flap kick & $\cdot$ & 1 &. .111 & $\because \varepsilon \cdot \varepsilon$ & 1.94 \\
\hline
\end{tabular}

Table (3)

Equivalent sample search for the variables of age, weight and height

\begin{tabular}{|c|c|c|c|c|c|c|}
\hline & \multicolumn{2}{|c|}{ Experimental } & \multicolumn{2}{|c|}{ Control } & \multirow{2}{*}{ difference } & \multirow{2}{*}{$\mathbf{T}$} \\
\hline & mean & Std. & mean & Std. & & \\
\hline Age & 19.2 & 4.11 & 18.9 & 4.2 &.$r$ & . AVOY \\
\hline the weight & 12.25 & 1.2 & 12.01 & 1.5 & $\because r \leqslant$ & . rqM _ \\
\hline Length & 70.11 & 1.16 & $V V .71$ & $1.1 \mathrm{~V}$ & $V . O_{-}$ &. $.1 \vee \Lambda_{-}$ \\
\hline
\end{tabular}

It is clear from Table (3)

significant differences between that there are no statistically the experimental group and the 


\section{2}

control group in the age, height and weight variables, which means equal sampling for the research.

Table (4)

Equivalent sample research in the mental health of infants (experimental and controlling)

\begin{tabular}{l|c|c|c|c|c|c}
\hline \hline & \multicolumn{2}{|c|}{ Experimental } & \multicolumn{2}{c|}{ Control } & & \multirow{2}{*}{} \\
\cline { 2 - 5 } & mean & Std. & mean & Std. & difference & T \\
\hline \hline Sleep system & 5.08 & 1.16 & 5.33 & 1.07 & -0.250 & -.547 \\
\hline eater & 5.75 & 1.29 & 5.83 & 1.53 & -0.083 & -.144 \\
\hline Emotional system & 6.83 & 1.11 & 7.25 & 1.22 & -0.417 & -.875 \\
\hline Curiosity, interest and attention & 6.33 & 1.07 & 6.50 & 1.00 & -0.167 & -.394 \\
\hline Motor activity & 5.00 & 1.21 & 5.08 & 1.08 & -0.083 & -.178 \\
\hline Communication and interaction & 5.67 & 1.67 & 5.50 & 1.09 & 0.167 & .290 \\
\hline The language & 4.67 & 0.89 & 4.25 & 0.97 & 0.417 & 1.101 \\
\hline Total & 39.33 & 4.35 & 39.75 & 2.49 & -0.420 & -0.288 \\
\hline \hline
\end{tabular}

From Table (4), it is

clear that there are no statistically significant differences between the experimental group and the control group in the mental health scale for infants, which means parity of the sample.

Data collection tools and means:

1- Experts poll to determine swimming skills suitable for infants : The researcher was satisfied with swimming skills that reached a percentage of more than $80 \%$, which is (confidence in water self-suppression $15 \mathrm{w}$ - floating on the abdomen - floating on the back - swirling in the water - holding the edge of the pelvis - switching from floating on the back to the abdomen - kick the flap )

2- The scale of mental health indicators for infants: The researcher has adopted the psychological and mental health scale prepared by Jani Amitzbull and others (2016) Janni Ammitzbøll (10) The researcher has translated it into Arabic

3- $\quad$ Expert Opinion Survey Form on the Safety Education Program in Water for Babies: The researcher was satisfied with $80 \%$ or more of these results, and thus (the duration of the program is 8 weeks - number (2) educational unit per week - the unit time for education is 35 minutes)

Survey study:

The researcher conducted the exploratory study in the 
time period $4 / 5 / 2018$ to $15 / 5 / 2018$ on a survey sample consisting of (12) infants from the research community, and from outside the core sample, and aimed at conducting scientific transactions for a form to assess the skill level and mental health scale for infants

\section{Coefficient of honesty:}

The researcher used the sincerity of the distinction between two groups equal in number, one of which is a distinct group consisting of (6) infants from (12-24) months, and the other group is not distinguished and consists of (6) infants (12-24) months (exploratory research sample) who are from academies (Baby swimming Egypt) in the fifth assembly, the value of $(\mathrm{T})$ was calculated between the members of the distinct and non-distinct groups in the skill variables and the mental health scale for infants.

\section{Table (5)}

The significance of the differences between the distinct and unrecognized groups in the skill variables

\begin{tabular}{|c|c|c|c|c|c|c|}
\hline & \multicolumn{2}{|c|}{ Special } & \multicolumn{2}{|c|}{ indiscriminate } & \multirow[t]{2}{*}{ difference } & \multirow[t]{2}{*}{$\mathbf{T}$} \\
\hline & mean & Std. & mean & Std. & & \\
\hline Trust in water & $\varepsilon . \wedge \wedge$ & $1 . V 1$ & $1 . \varepsilon$ & $1 . \wedge$ & $r . \leqslant 1$ & 0.10 \\
\hline Mute self $15 \mathrm{w}$ & 4.97 & $1 . \leqslant 7$ & 1.9 & 1.19 & r. 9. & $V .07$ \\
\hline Buoyancy of the abdomen & r.^. & 1.00 &.$\wedge 1$ & .99 & $r .99$ & $\varepsilon . \Gamma_{0}$ \\
\hline Floating on the back & $\varepsilon .1 T$ & $r .$. & 1.1 & $1 . \leqslant \varepsilon$ & $r . \wedge r$ & 9.07 \\
\hline Water circulation & r.t人 & 1.0 &.$V T$ & .9 & 1.70 & $V .07$ \\
\hline Hold the edge of the pool & $1 . \leqslant 7$ &.$V V$ & .07 & .70 & .9 & 7.05 \\
\hline $\begin{array}{l}\text { Switch from floating on } \\
\text { the back to the abdomen }\end{array}$ & $1 .{ }^{\prime}$ & $\because V^{\circ}$ & .70 & .77 &.$V T$ & $\varepsilon . \wedge 0$ \\
\hline Flap kick & 1.41 & .77 & $\because \leqslant \wedge$ &.$\leqslant 0$ &.$V T$ & $0.7 \varepsilon$ \\
\hline
\end{tabular}

It is clear from Table (5) that there are statistically significant differences at the level of 0.05 between the two distinct and non-distinct groups in the physical variable under discussion between the distinct group and the non-distinct group in favor of the distinct group, which indicates the sincerity of these variables for what was set for it.

Table (5)

The significance of the differences between the distinct and unrecognized groups in the skill variables 


\begin{tabular}{l|l|l|l|l|l|c}
\hline \hline & \multicolumn{2}{|c|}{ indiscriminate } & \multicolumn{2}{c|}{ Special } & difference & \multirow{2}{*}{ T } \\
\cline { 2 - 6 } & mean & Std. & mean & Std. & & \\
\hline \hline Sleep system & 5.58 & 1.365 & 8.150 & 1.128 & 2.567 & 4.721 \\
\hline eater & 6.25 & 1.488 & 7.983 & 2.865 & 1.733 & 2.315 \\
\hline Emotional system & 7.33 & 1.315 & 9.900 & 1.118 & 2.567 & 4.745 \\
\hline Curiosity, interest and attention & 6.83 & 1.273 & 10.400 & 1.372 & 3.567 & 7.124 \\
\hline Motor activity & 5.50 & 1.406 & 8.817 & 1.301 & 3.317 & 6.912 \\
\hline Communication and interaction & 6.17 & 1.870 & 9.483 & 1.772 & 3.317 & 5.553 \\
\hline The language & 5.17 & 1.088 & 7.483 & 1.074 & 2.317 & 6.452 \\
\hline Total & 39.83 & 4.550 & 62.817 & 5.220 & 22.987 & 12.442 \\
\hline \hline
\end{tabular}

It is clear from Table (5)

that there are statistically significant differences at the level of 0.05 between the two distinct and non-distinct groups in the physical variable under discussion between the distinct group and the non-distinct group in favor of the distinct group, which indicates the validity of the mental health scale

Stability coefficient: The researcher calculated the Table (6)
$\begin{gathered}\text { correlation coefficient between the first and second application of } \\ \text { the exploratory sample in the skill variables }\end{gathered}$

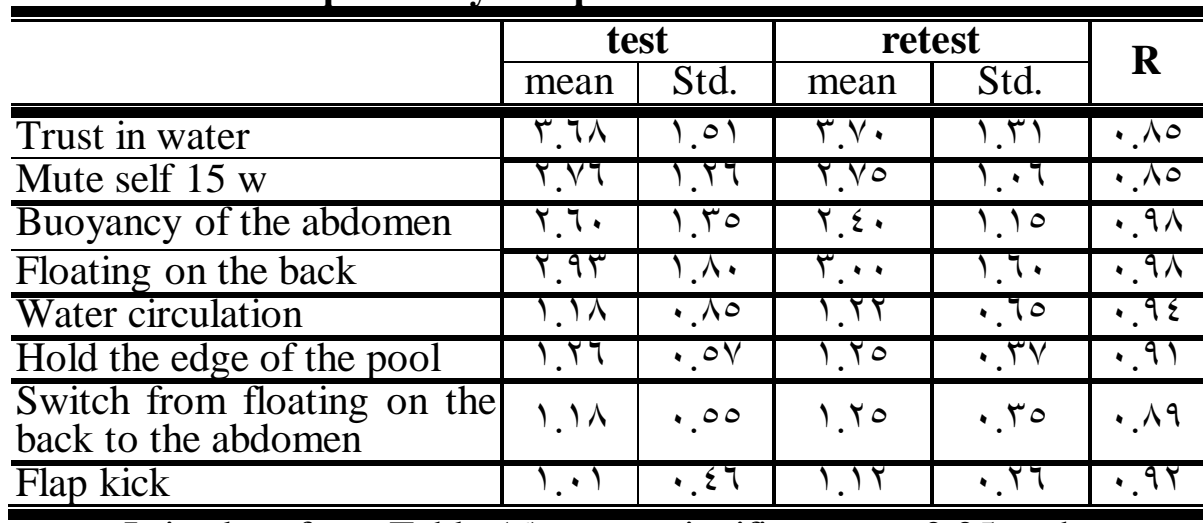
It is clear from Table (6) that there is a correlation relationship with statistical significance at the level of stability coefficient using the test application method and then repeated it with a time interval of three days from the variables under consideration in the period from $1 / 5 / 2018$ to $5 / 15 / 2018$ provided that the simple correlation coefficient between the results of the two applications is calculated the first and the second first application of the skill 
consideration, which indicates the stability of these tests.

The researcher calculated the coefficient of persistence by using Alpha Kornbach to measure mental health, where he achieved (. 0963)

Research executive procedures:

befor measurement: The researcher performed the tribal measurement of the experimental group and the control in the mental health scale under investigation during the period from $17 / 5 / 2018$ AD. The researcher conducted the tribal measurement of the experimental group in the skill variables under consideration, corresponding to $18 / 5 / 2018$, according to the specifications and performance conditions For each test.
Application educational
of
the
Results

researcher applied the proposed educational program in its final form to the experimental group, in the period from $5 / 19 / 2018$ to $8 / 8 / 2018$, and for a period of (12) weeks, and by two educational units each week.

After measurement: After completing the specified period for the implementation of the proposed educational program in the research group, the researcher conducted the post-measurement with the same conditions and specifications that were done in the pre-measurement, in order to ensure the accuracy and integrity of the data, on $08 / 10 / 2018$ for the skill variables of the experimental group and on 8/11/2018 in the mental health scale for the experimental and control group

Table (8)

Indicating the differences between the two dimensional measures of the control and experimental group in the infant mental health scale

\begin{tabular}{l|c|c|c|c|c|c}
\hline \hline & \multicolumn{2}{|c|}{ Control } & \multicolumn{2}{c}{ Experimental } & difference & \multirow{2}{*}{ T } \\
\cline { 2 - 6 } & mean & Std. & mean & Std. & & \\
\hline \hline Sleep system & 8.2500 & 1.13818 & 5.667 & 1.073 & 2.5833 & 5.721 \\
\hline eater & 8.0833 & 2.87492 & 6.000 & 1.206 & 2.0833 & 2.315 \\
\hline Emotional system & 10.0000 & 1.12815 & 7.250 & 1.215 & 2.7500 & 5.745 \\
\hline Curiosity, interest and attention & 10.5000 & 1.38170 & 6.500 & 1.000 & 4.0000 & 8.124 \\
\hline Motor activity & 8.9167 & 1.31137 & 5.417 & 0.793 & 3.5000 & 7.912 \\
\hline Communication and interaction & 9.5833 & 1.78164 & 5.750 & 0.965 & 3.8333 & 6.553 \\
\hline The language & 7.5833 & 1.08362 & 4.417 & 0.996 & 3.1667 & 7.452 \\
\hline Total & 62.9167 & 5.23030 & 41.000 & 2.132 & 21.9167 & 13.442 \\
\hline \hline
\end{tabular}

It is clear from Table (8) that there are statistically significant differences at the level of significance. 05 where the calculated $\mathrm{T}$ value was greater than the tabular $\mathrm{T}$ value in all indicators of mental health of infants (for the 
experimental group compared to the control group and that did not use any educational programs

The researcher indicates that the improvement of all mental health indicators for infants is due to the educational program that was subjected to the experimental group compared to the control group, and this is consistent with what you refer to as the results of the study of both Philip, R. et-al (2006) (41) and it was one of the most important The results of this study indicate that swimming positively affects children's behavior and access to organized behavior

She also agreed with the study of Hermundur (2009)

\section{Table (9)}

shows the significance of the differences between the pre and post measurement of the experimental group in the skill performance level

\begin{tabular}{|c|c|c|c|c|c|c|}
\hline & \multicolumn{2}{|c|}{ before } & \multicolumn{2}{|c|}{ after } & \multirow[t]{2}{*}{ 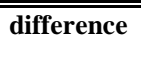 } & \multirow[t]{2}{*}{$\mathbf{T}$} \\
\hline & mean & Std. & mean & Std. & & \\
\hline Trust in water & $\overline{.750}$ & .965 & 7.500 & 1.000 & $\overline{6.75}$ & -16.823 \\
\hline Mute self $15 \mathrm{w}$ & .583 & .996 & 7.500 & 1.087 & 6.92 & -16.249 \\
\hline Buoyancy of the abdomen & .417 & .669 & 7.417 & .793 & 7.00 & -23.379 \\
\hline Floating on the back & .750 & .754 & 8.750 & .754 & 8.00 & -25.997 \\
\hline Water circulation & .250 & .452 & 3.917 & .793 & 3.67 & -13.914 \\
\hline Hold the edge of the pool & .167 & .389 & 2.417 & .793 & 2.25 & -8.824 \\
\hline Switch from floating on the back to the abdomen & .333 & .492 & 2.167 & .718 & 1.83 & -7.297 \\
\hline Flap kick & .167 & .389 & 2.083 & .515 & 1.92 & -10.286 \\
\hline $\begin{array}{l}\text { From tables (9), it is clear } \\
\text { that there are statistically } \\
\text { significant differences between } \\
\text { the measurements of the } \\
\text { research sample (pre- }\end{array}$ & & $\begin{array}{l}\text { din } \\
\text { val } \\
\text { din } \\
\text { all } \\
\text { in }\end{array}$ & ter & 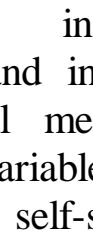 & $\begin{array}{l}\text { the } \\
\text { avor }\end{array}$ & $\begin{array}{l}\text { skill } \\
\text { the } \\
\text { s in } \\
\text { lence } \\
\text { n } 15\end{array}$ \\
\hline
\end{tabular}

Assiut Journal For Sport Science Arts 
w - buoyancy on the abdomen buoyancy on the back - rotation in Water - hold the edge of the pool - switch from floating on the back to the abdomen flutter kick).

The researcher attributes these differences to the educational program, which has an effective role in the development and acquisition of swimming skills for infants, as it contains training that represents the basic basis for developing and acquiring skills, which are favorable movements to the same infants and simple ones that they can perform easily in addition to the factors of suspense, encouragement,

encouragement and practice.

And the educational program used by the researcher has an effective impact on the acquisition of swimming skills for infants, as there is a diversity in the use of training and progression in teaching swimming skills from simple to complex and from easy to difficult, so it has had an effective impact in the education of infants.

Salma Al-Nashef (2003) (3) notes that a successful educational program explores the inherent capabilities, special preparations and skills and works to develop and encourage them, as it provides an opportunity to discover the individual himself and know his capabilities.

The researcher attributes this remarkable progress to the adoption of the educational program on the different teaching methods that encourage providing an element of suspense, excitement and enthusiasm for infants to learn swimming skills, and that the teaching method used contributes to infant learning of skill, because the child is the focus of the educational process as it allows him Greater opportunity for skill training in addition to developing the abilities associated with swimming skills (confidence in the water self-concealment $15 \quad \mathrm{~W}$ floating on the abdomen floating on the back - swirling in the water - holding the edge of the pool - switching from floating on the back to the abdomen - kick the flutter).

Containing the educational program on various educational elements and methods for its application has helped the sample members to make skillful progress, because the 
program contains confidence and familiarity exercises with water to feel reassured and thus reduce the degree of fear of water and this is consistent with what each of R Jorgensen indicated. Jorgensen (2012 CE) (42), Georgesias et al. Jorgedias, et-al (2013 CE) (31).

This is consistent with the results of both Philip and R. etal (2006) (41), Hermundur (2009) (30), and Jorgedias, etal (2013) (31) that the program contains activities Various exercises and progressive in difficulty, this diversity contributes effectively to learning swimming skills for infants.

Thus, the second hypothesis has been fulfilled, which states that there are statistically significant differences at the level of significance .05 between the pre and post measurements of the experimental group in the level of skill performance

\section{Conclusions:}

1- Effect of the proposed educational program effectively in learning swimming skills (confidence in water - self-concealment $15 \mathrm{w}$ floating on the abdomen floating on the back - swirling in the water- holding the edge of the pool- switching from floating on the back to the abdomen- flutter kick) for children Infants.

2- The effect of the proposed educational program effectively on improving the total sum of the infant mental health scale and its axes (sleep systemeating- emotional systemcuriosity, interest and attention -movement activitycommunication and interaction - language) compared to children who practice the educational program.

\section{Recommendations:}

1-Applying the educational program to all stages of infants. 2- The necessity of providing the clubs with a time designated for infants in the swimming pool.

3- That the programs include preparing the swimming teacher for the infant's swimming.

4- Carry out awareness programs for parents about the importance of swimming for infants.

\section{References:}

1- Brenner ,R.A .Gitanjali, S.T. Haynie ,D.L. Trumble ,A.C. Qian, C. Klinger ,R.M. Klebanoff, M.A. (2009): Association between swimming lessons and drowing in childhood "Acase controlstudy, Archives of 
pediatrics and Adolscent medicine , 163 (3)

2- Osama Kamel Ratib (1998): Swimming Education, 3rd floor, Arab Thought House, Cairo.

3- Mohamed Hussein AbdelMoneim (2009): Teaching swimming in the curricula of physical education, Dar AlWafa Dunia for Printing and Publishing, Alexandria.

4- Brenner ,R.A. Gitanjali, S.T. Haynie ,D.L. Trumble ,A.C. Qian, C. Klinger ,R.M. Klebanoff, M.A. (2009): Association between swimming lessons and drowing in childhood "Acase controlstudy, Archives of pediatrics and Adolscent medicine , 163 (3)

5- Brenner ,R.A .Gitanjali, S.T. Haynie ,D.L. Trumble ,A.C. Qian, C. Klinger ,R.M. Klebanoff, M.A. (2009): Association between swimming lessons and drowing in childhood "Acase controlstudy, Archives of pediatrics and Adolscent medicine , 163 (3)

6- Costello EJ, Egger H, Angold : A. 10-year research update review, the epidemiology of child and adolescent psychiatric disorders: I. Methods and public health burden. J Am Acad Child Adolesc Psychiatry. 2005;44:972-86.

7- Dennison ,P.E. (2015) :Message the brain -button and learn, news magazine onlinewww.ehostevgw3.epnet.c $\mathrm{om} /$ fulltext. aspresultsetld=R000 00002\&hitnum $=5 \&$ booleanTer .

8- German Sports college cologne (1979): Advance independence and development of intelligence "world aquatic babies and children network, online -www.wabc.com

\section{9- Healthmade Magazine} (2011): the benefits for swimming especially for children - the function to teach swimming to infants .

10- Hermundur sigmundsson (2009): baby swimming " exploring the effect of early intervention on subsequent motor abilities university of science and technology, Norwegian.

11- Janni Ammitzbøll, Bjørn E. Holstein, Lisbeth Wilms, Anette Andersen and Anne Mette Skovgaard: A new measure for infant mental health screening: development and initial validation Ammitzbøll et al. BMC Pediatrics (2016) 16:197 DOI 10.1186/s12887-016-0744-1

12- Jorgensen, R. groorenbeer ,P. funnel, $B$. 
(2011) : early years swimming, research project at Griffith university, splash magazine.

13- Kramer, A.F. Erickson ,K.L.Colcumbs, S.J. (2009): Exercise, cognition and the aging brain, journal of Applied physiology.

14- Martins, marta, siva. Antonio J, Daniel .A (2010): assessment of heart rate during infant swim session international sportmed journal, vol (11), issue 3, p336- p344. 15- Natalie Garcia bartels Etal (2011): Effect of baby swimming and baby lotion on the skin barrier or infants aged 3-6 months, berlin university, german.

16- Philip R.Zelazo, Michael J. Weiss (2006): infant swimming behaviors cognitive control and the influence of experience, journal of cognition and development, mc gill university, canada.

17- Rice R., (1977): "Neurophysiological

Development in Premature
Neonate Following Stimulation." Developmental Psychology, 13 18- Rosengren L., (2004) :Baby Swim: The Beginning of a Life Long Adventure. Uppsala, Sweden. Uppsala Publishing house.

\section{9- Rutter M, Kim-Cohen J,} Maughan B. : Continuities and discontinuities in psychopathology between childhood and adult life. J Child Psychol Psyc. 2006;47:276-95.

20- Sigmundsson, H. Hopkins ,B. (2010): baby swimming exploring the effects of early intervention on subsequent motor abilities "child care-health and development, science daily, 36(3)

21- Zalazo , P.R. Weiss, M.J, (2006): infant swimming behaviors "cognative control and influence of experience", journal of cognitive development, 7 (1) . 